\title{
Age-dependent incidence, time course, and consequences of thymic renewal in adults
}

\author{
Frances T. Hakim, ${ }^{1}$ Sarfraz A. Memon, ${ }^{1}$ Rosemarie Cepeda, ${ }^{1}$ Elizabeth C. Jones, ${ }^{2}$ \\ Catherine K. Chow, ${ }^{2}$ Claude Kasten-Sportes, ${ }^{1}$ Jeanne Odom, ${ }^{1}$ Barbara A. Vance, ${ }^{1}$ \\ Barbara L. Christensen, ${ }^{3}$ Crystal L. Mackall, ${ }^{3}$ and Ronald E. Gress ${ }^{1}$
}

${ }^{1}$ Experimental Transplantation and Immunology Branch, National Cancer Institute, ${ }^{2}$ Diagnostic Radiology, Clinical Center, and ${ }^{3}$ Pediatric Oncology Branch, National Cancer Institute, NIH, Bethesda, Maryland, USA.

\begin{abstract}
Homeostatic regulation of $T$ cells involves an ongoing balance of new $T$ cell generation, peripheral expansion, and turnover. The recovery of $T$ cells when this balance is disrupted provides insight into the mechanisms that govern homeostasis. In a long-term, single cohort study, we assessed the role of thymic function after autologous transplant in adults, correlating serial computed tomography imaging of thymic size with concurrent measurements of peripheral $\mathrm{CD4}^{+} \mathrm{T}$ cell populations. We established the age-dependent incidence, time course, and duration of thymic enlargement in adults and demonstrated that these changes were correlated with peripheral recovery of naive $C D 45 R A^{+} C D 62 L^{+}$and signal-joint TCR rearrangement excision circle-bearing $\mathrm{CD}^{+}$populations with broad TCR diversity. Furthermore, we demonstrated that renewed thymopoiesis was critical for the restoration of peripheral $\mathrm{CD}^{+} \mathrm{T}$ cell populations. This recovery encompassed the recovery of normal $\mathrm{CD}^{+} \mathrm{T}$ cell numbers, a low ratio of effector to central memory cells, and a broad repertoire of TCR $V \beta$ diversity among these memory cells. These data define the timeline and consequences of renewal of adult thymopoietic activity at levels able to quantitatively restore peripheral $\mathrm{T}$ cell populations. They further suggest that structural thymic regrowth serves as a basis for the regeneration of peripheral $\mathrm{T}$ cell populations.
\end{abstract}

\section{Introduction}

Recent studies have demonstrated that maturation of new $\mathrm{T}$ cells in the human thymus continues throughout life. Although extremely active in the fetal and perinatal period, the thymus continues to generate new $\mathrm{T}$ cells into the adult years and even into old age, exporting phenotypically naive or TCR excision circle-bearing (TREC-bearing) cells into the peripheral blood (1-3). Even in the elderly, naive T cells express a broad TCR repertoire, supplying the diversity needed to respond to antigenic challenge $(2,4)$. Yet aging has quantitative if not qualitative effects on thymopoiesis. The thymus undergoes a progressive physiological involution with aging that alters its structure and cytokine milieu $(5,6)$. The production of naive $T$ cells dwindles as the thymus progressively involutes into strands of medullary and cortical cells surrounded by adipose and connective tissue (7). As the productive capacity of the thymus lags, the frequency of naive cells gradually is reduced. Overall $\mathrm{T}$ cell levels are maintained nonetheless by a variety of peripheral thymus-independent homeostatic mechanisms (8). Long-lived naive $\mathrm{T}$ cells proliferate at a low rate in response to low-affinity antigens $(9,10)$. Memory T cells turn over at a higher rate than do naive cells, but are continuously replaced by ongoing cytokine-driven proliferation $(11,12)$. Finally, newly activated naive and memory cell populations expand in response to cognate antigenic stimulation and occupy increased fractions of the repertoire (13).

Nonstandard abbreviations used: ANC, absolute neutrophil count; APBSCT, autologous peripheral blood stem cell transplant; $\mathrm{BC}, \beta$-constant region; CM, central memory; CT, computed tomography; EM, effector memory; ETP, early thymic progenitor; GH, growth hormone; HAART, highly active antiretroviral therapy; RTE, recent thymic emigrant; sjTREC, signal-joint TREC; TI, thymic size index; TREC, TCR rearrangement excision circle.

Conflict of interest: The authors have declared that no conflict of interest exists.

Citation for this article: J. Clin. Invest. 115:930-939 (2005)

doi:10.1172/JCI200522492.
It is only in the setting of severe $\mathrm{T}$ cell depletion, through HIV infection or cytoreductive transplant or chemotherapy regimens, that the role of the thymus in $\mathrm{T}$ cell homeostasis becomes critical and that the degree of insufficiency of the adult thymus becomes apparent. The early response to severe lymphodepletion (depletion of lymphocytes through chemotherapy or transplant conditioning regimens) is dominated by peripheral expansion of mature $\mathrm{T}$ cell populations, including those remaining in the host or contained in $\mathrm{T}$ cell-replete donor grafts or delayed lymphocyte infusions (14-17). These expansions are often transient, however, with high levels of $\mathrm{T}$ cell turnover and apoptotic susceptibility $(16,18-20)$. Renewal of thymopoiesis, as evidenced by increases in phenotypically naive or TREC-bearing cells in the peripheral blood, has been reported $(15,21,22)$. Yet long-term deficits, particularly of $\mathrm{CD}^{+}$ $\mathrm{T}$ cells, have been observed in many adults after cytoreduction $(16,23,24)$. The constraints on the capacity of the adult immune system to reconstitute normal populations, especially over prolonged periods of time, remain incompletely understood.

In the young, recovery of depleted naive cells is correlated with increases in thymic cellularity and volume, termed "thymic rebound," that are evident within the first few months after chemotherapy (25). The potential for similar structural changes in the thymus in adults has not been explored in a prospective long-term study. Thymic rebound at 6 months after treatment is markedly reduced in young adults compared with children (25). Thymic enlargement is observed in less than $10 \%$ of adults in the early months after transplant $(25,26)$. Reports of HIV patients, however, suggest that the adult thymus can expand after as much as a year after the initiation of highly active antiretroviral therapy (HAART) (27-29). Recovery of T cells, in particular $\mathrm{CD}_{4}^{+}$cells, from severely cytoreductive regimens is a protracted process in adults. Levels of TREC-bearing recent thymic emigrants (RTEs) in the peripheral blood continue to rise for at least 2 years after autologous 

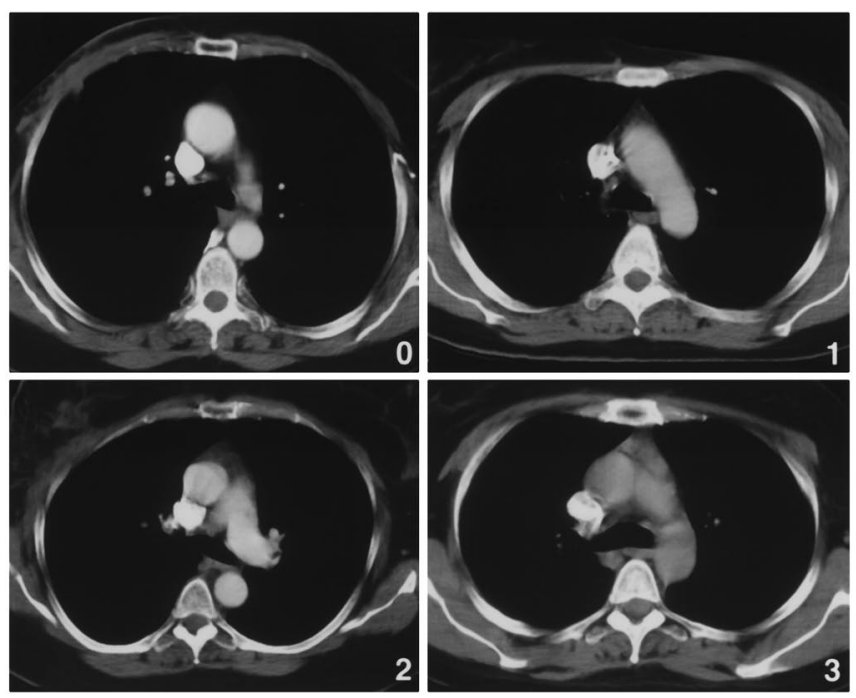

transplant $(22,30)$. If thymic structural expansion follows a similarly prolonged time course, then a longer course of serial measurements would be needed than has been attempted so far.

We report here on prospectively monitoring the recovery of thymic function over 2-5 years by a multiparameter analysis of a single cohort of adult patients treated for breast cancer by autologous peripheral blood stem cell transplant (APBSCT). This protocol had the advantage that the route and time course of lymphocyte recovery could be established without the confounding factors of hematologic malignancy, allogeneic reactivity, or immunosuppressive drugs (31-33). We assessed thymic structural change by serial thoracic computed tomography (CT) scans at intervals of 6 months and correlated these with measurements of effective thymopoiesis by concurrent analysis of naive and memory phenotype cells by flow cytometry. We then assessed RTEs by TREC analysis and TCR diversity by spectratyping after 24 months. With these coordinated studies we evaluated the consequences of thymic renewal on overall $\mathrm{CD} 4^{+} \mathrm{T}$ cell recovery and re-establishment of a diverse functional TCR repertoire in adults.

\section{Results}

Incidence and time course of renewal of thymopoiesis is age dependent among adults. We assessed thymic structural change during the reconstitution of $\mathrm{CD}^{+} \mathrm{T}$ cells by examination of serial thoracic CT scans using a 4-point thymic size index (TI) (Figure 1) $(27,28)$. Thymic soft tissue mass was extremely reduced in most patients by the end of transplant conditioning (TI of 0 or 1 ). In 20 of 32

\section{Figure 2}

Effect of age on recovery of thymic size after APBSCT. (A) Spearman nonparametric correlation demonstrates that the maximum $\mathrm{TI}$ achieved in the first 2 years after transplant (as assessed in Figure 1) is dependent on age at time of treatment. (B) Time course of thymic enlargement as stratified by age. Each line represents the individual time course during the first 2 years after transplant of changes in TI of a patient who achieved a maximum $\mathrm{Tl}$ of 2 , the size of a normal adult thymus. The number of patients in each age range and the incidence of those individuals with thymic enlargement ( 4 of $5, \mathrm{Tl} \geq 2$ ) is in parentheses above each graph. The gray bands represent the range of minimal thymic size observed after transplant in patients demonstrating no significant change, whose time courses would otherwise overlap.

\section{Figure 1}

TI scale utilized to assess thymic enlargement in thoracic CT scans, based on McCune (28): 0, no soft tissue with thymus entirely replaced by fat (top left panel); 1 , minimal soft tissue, barely recognizable (top right panel); 2, minimal soft tissue more obvious (typical thymus of a middle-aged adult; bottom left panel); 3, moderate soft tissue (bottom right panel). No cases of McCune's level 4 (moderate soft tissue of greater extent, almost mass-like) or level 5 (mass-like appearance of concern for hyperplasia or thymoma) were observed in these patients.

autologous transplant patients, thymic size remained minimal (TI of 0 or 1) after transplant. Twelve of the patients studied, however, demonstrated an increase in thymic size, attaining a maximum TI of or above 2, the size of the typical thymus in middle-aged adults (28). Furthermore, 7 patients achieved a TI of at least 3, a significantly larger thymic profile with moderate cellularity. This change in size and radiodensity is particularly remarkable, given that only 2 of these 12 patients had a TI of 3 prior to the start of therapy. The pretreatment TI values of the remaining 10 patients ranged from 0 to 1.5 . Thus, the development of a radiodense thymic profile after transplant in these patients represented not merely a return to the pretreatment status but to a higher level than their pretreatment TI values.

In the 32 individual patients examined, the maximum thymic size attained during the first 2 years of follow-up was age dependent (Figure 2A). Furthermore, when stratified by age (in decades), the incidence and rate of thymic enlargement were also clearly linked to age (Figure 2B). In 4 of 5 of the patients 30-39 years of age, a significant thymic enlargement was evident; in 3 of these, maximum size was reached by 6 months and all 4 eventually reached a TI of 3 . The incidence of thymic enlargement dropped to only 6 of 13 patients among those 40-49 years of age, the onset of enlargement was delayed, the time course was more protracted, and only 2 reached a TI of 3 . In patients over 50 years of age, only 2 of 14 (51 and 64 years of age) demonstrated any thymic enlargement from the treatment nadir; in the elder of these, thymic enlargement proceeded very slowly and achieved the size of a middle-aged adult thymus only at the end of 2 years. No further increases in size were observed after 2 years, although some enlarged thymuses declined in size. The number of months required to achieve the size of a normal middle-aged adult thymus (a TI of 2) was com-
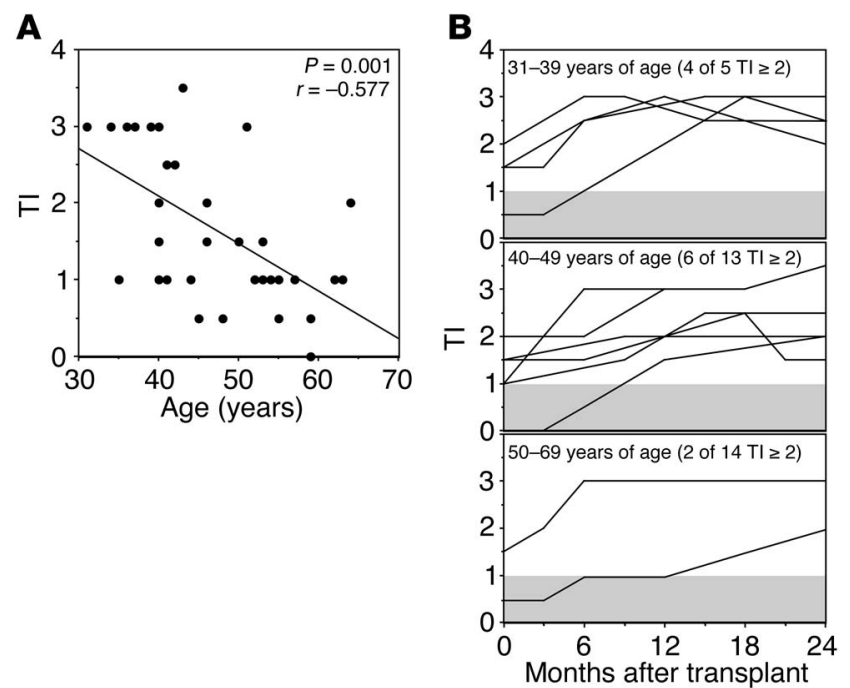

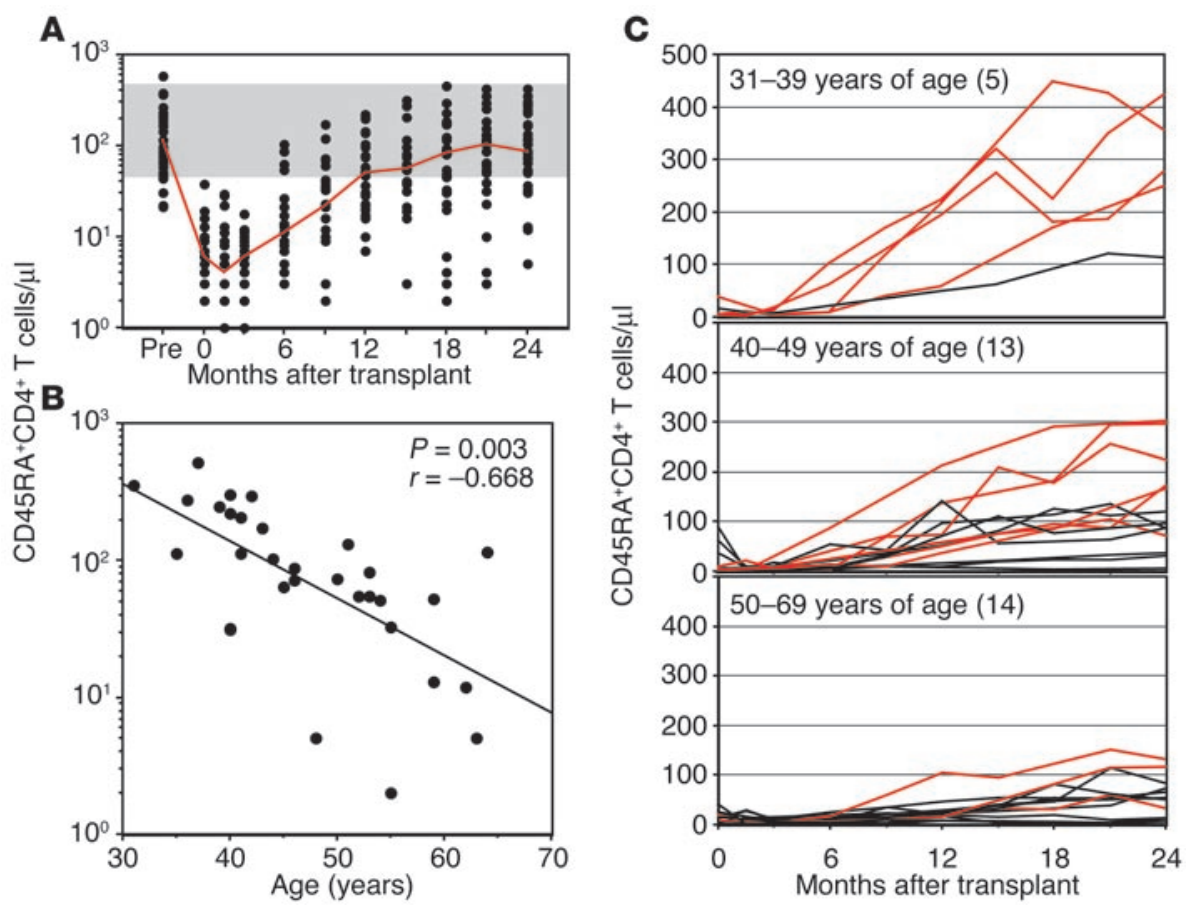

6-12 months after transplant in patients in 3 of 5 patients in their 30s. In the 3 of 13 patients in their 40s who achieved a level of 200 cells/ $\mu$, this degree of recovery was delayed into the second year. No patient over 50 years recovered a level of 200 naive cells/ $\mu 1$ within 2 years after transplant. The average level of naive $\left(\mathrm{CD}^{2} 5 \mathrm{RA}^{+} \mathrm{CD} 62 \mathrm{~L}^{+}\right) \mathrm{CD}^{+} \mathrm{T}$ cells that was achieved within 2 years was 307 cells/ $\mu \mathrm{l}$ in patients in their 30s, but declined to 131 and to 51 in successive decades. Thus, the incidence of patients with a marked recovery of naive cells, the total level of naive $\mathrm{CD}^{+} \mathrm{T}$ cells achieved over 2 years, and even the overall time course of naive $\mathrm{T}$ cell recovery was age dependent (Figure 3C).

Although tracking of recovering populations by flow cytometry has been widely used after transplant, concerns exist about proliferative expansion of phenotypically naive cell populations or re-expression of naive markers. (35) We further corroborated the emergence of newly matured $\mathrm{T}$ cells from the thymus (RTEs) by quantitative PCR of TRECs in peripheral blood $\mathrm{CD}^{+} \mathrm{CD}^{+} \mathrm{T}$ cells. We focused mainly on patients at 21-24 months after transplant. TREC levels reached a maximum of over 10,000 TRECs per $10^{5} \mathrm{CD}^{+}$cells at 2 years in some patients (Figure 4). In many patients, however, TREC levels remained low, not increasing beyond 1,000 per $10^{5}$ $\mathrm{CD} 4^{+}$cells by 2 years. Just as with TI and

pared in the 3 age groups using nonparametric survival analysis. Significant differences in thymic recovery time were observed in the 3 age groups $(P=0.0024$; Mantel-Cox log-rank).

Because more than $95 \%$ of naive $\mathrm{CD}^{+} \mathrm{T}$ cells are lost during transplant regimens, the reappearance and increase of phenotypically naive $T$ cells after transplant can provide an estimate of recovery of newly matured cells and hence an assessment of thymic function $(16,25,34)$. After APBSCT, levels of naive $\left(\mathrm{CD} 45 \mathrm{RA}^{+} \mathrm{CD} 62 \mathrm{~L}^{+}\right)$ $\mathrm{CD}^{+} \mathrm{T}$ cells remained low, with a median value below $25 \mathrm{cells} / \mu \mathrm{l}$ in the first 9 months (Figure 3A). In most patients, naive cells remained less than $25 \%$ of the total for the first 2 years and absolute levels were well below pretreatment levels (Figure 3A). In some patients, however, this population increased sharply by the end of the first year, reaching $50 \%$ of the total $\mathrm{CD} 4^{+}$population and returning to normal levels of naive cells in the second year. Consistent with the pattern of thymic enlargement, the production of naive cells at the end of 2 years was strongly age dependent even within this middle-aged cohort of patients (Figure 3B). Patients with evident thymic enlargement (Figure $2 \mathrm{~B}$ ) tended to have the highest levels of $\mathrm{CD}^{+} \mathrm{T}$ cells with a naive phenotype (red lines in Figure 3C). Furthermore, with each decade of patient age, the percentage of patients demonstrating a vigorous recovery of naive $\mathrm{T}$ cells and even the rate of that recovery declined (Figure 3C). For example, recovery of naive cell levels to 200 cells/ $\mu$ l occurred within the percentages of naive cells, the frequency of signal-joint TRECs (sjTRECs) had recovered beyond pretreatment levels, increasing to $4,559 \pm 1,189$ sjTRECs per $10^{5} \mathrm{CD}^{+} \mathrm{T}$ cells, compared with pretreatment levels that averaged 2,264 \pm 461 . Furthermore, as with other assays of thymic recovery, the level of TRECs per $10^{5} \mathrm{CD} 4^{+}$ cells at 2 years strongly correlated with the age of the patients (Figure 4). These data confirm that even in a patient cohort composed of middle-aged adults, age affects the capacity of the thymus to reinitiate thymopoiesis sufficient to quantitatively affect the size of the RTE pool in peripheral $\mathrm{CD}^{+} \mathrm{T}$ cell populations.

In patients with significant increases in thymic size, parallels in the time courses of thymic enlargement and naive $\left(\mathrm{CD} 45 \mathrm{RA}^{+} \mathrm{CD}_{62} \mathrm{~L}^{+}\right) \mathrm{CD}^{+} \mathrm{T}$ cell numbers in the peripheral blood (red lines in Figure 3C) supported the idea of a link between these independently determined parameters. We therefore tested the correlations between the maximum thymic index, which usually was achieved by 1 year, and naive $\mathrm{CD}^{+} \mathrm{T}$ cell recovery. Maximum thymic index was predictive of both the number of naive $\left(\mathrm{CD} 4 \mathrm{RA}^{+} \mathrm{CD} 2 \mathrm{~L}^{+}\right) \mathrm{CD}^{+} \mathrm{T}$ cells and the frequency of TRECs per $10^{5} \mathrm{CD}^{+} \mathrm{T}$ cells at 2 years (Figure $5, \mathrm{~A}$ and $\mathrm{B}$ ). We also found a strong correlation between the number of naive $\left(\mathrm{CD} 45 \mathrm{RA}^{+} \mathrm{CD} 62 \mathrm{~L}^{+}\right)$ $\mathrm{CD}^{+} \mathrm{T}$ cells and the frequency of $\mathrm{CD} 4^{+}$TRECs at 2 years (Figure 5C), supporting the widespread use of FACS phenotyping to estimate thymic-dependent $\mathrm{CD}^{+}{ }^{+} \mathrm{T}$ cell reconstitution (25). The 


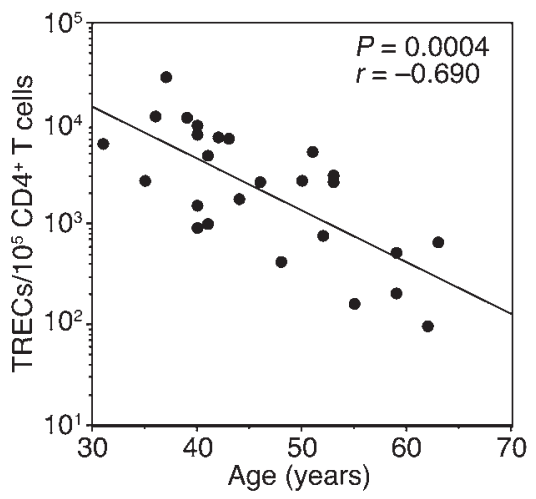

Figure 4

Effect of age on recovery of TREC-bearing CD4+ T cells. TREC frequency after approximately 2 years (21-24 months) is dependent on age at time of transplant.

linkage between thymic index change and peripheral measures of RTEs supports the hypothesis that the thymic expansion represented active thymopoiesis.

Recovery of repertoire diversity. The acute depletion of $\mathrm{T}$ cells accompanying chemotherapy or transplant conditioning regimens also results in a severe loss in the diversity of the TCR repertoire $(22,30,34,36-39)$. We separately assessed the recovery of repertoire in a limited number $(100,000)$ of sorted naive $\left(C D 45 \mathrm{RA}^{+}\right)$and memory (CD45RA-) $\mathrm{CD}^{+} \mathrm{T}$ cells by spectratyping, an RT-PCRbased measurement of length heterogeneity in the CDR3 domain of the TCR $\beta$ chain $(30,34,36,37,39)$. We focused on isolated naive $\mathrm{CD}^{+} \mathrm{T}$ cells because recovery of repertoire diversity would be solely dependent upon renewed thymopoiesis. Normalization of spectratype in total $\mathrm{T}$ cell populations, in contrast, could be associated not only with renewed thymopoiesis but also with apoptotic losses of activated, oligoclonally expanded $\mathrm{T}$ cell populations, or shifts in CD4-to-CD8 ratios, as CD8 spectratypes are more skewed than CD4 spectratypes.

Four patients identified by FACS as having significant recovery of naive T cells after transplant (50\% naive cells by 12 months) were analyzed at 3 time points during the first 18 months. Equal numbers $(100,000)$ of naive and memory CD4 T cells were separately analyzed for CDR3 length diversity within each of 23 TCR $\mathrm{V} \beta$ gene families at each time. In assays performed in the first 3-6 months after transplant, the repertoire diversity of both the $\mathrm{CD}^{-} 5 \mathrm{RA}^{+}$and the CD45RA- populations was severely limited (Figure 6). Multiple $V \beta$ families were not measurable at all or were limited to only a few irregular CDR3 peaks. The repertoire diversity in the CD45RA+ subpopulations recovered over the first 18 months after transplant, as demonstrated by steady increases in the number of peaks in the spectratypes (Figure 6). Thus the emergence of RTEs into the periphery restored the repertoire diversity of the naive $\mathrm{CD} 4^{+} \mathrm{T}$ cell pool. Recovery of the naive cell repertoire was followed by repertoire recovery of the CD45RA- memory populations in these individuals with a strong renewal of thymopoiesis (see below).

Thymus-dependent recovery of $\mathrm{CD} 4^{+} \mathrm{T}$ cells. The overall time courses of $\mathrm{CD}^{+} \mathrm{T}$ cell recovery in individual patients in the treatment cohort demonstrated a broad range of CD4 recovery (Figure 7A). Fluctuations occurred in the first few months, although not as marked as has been observed previously after chemotherapy, when the number of residual $\mathrm{T}$ cells at end of therapy was higher (16). Nevertheless, during the second year, the recovery courses of patients with strongly renewed thymopoiesis, shown in red in Figure 7A for individuals with a frequency of 3,000 or more TRECs per $10^{5} \mathrm{CD}^{+}$cells by 2 years, diverged from those with more limited thymic recovery. Only those individuals with robust renewal of thymopoiesis consistently maintained CD4 T cell numbers greater than 500 cells/ $\mu$ l by 2 years. In contrast, in those with limited renewal of thymopoiesis, $T$ cell levels would remain low even into the fourth and fifth years (see below).

This divergence is consistent with a critical role for thymopoiesis in the long-term recovery of total $\mathrm{CD}^{+} \mathrm{T}$ cell populations. After 2 years, the overall recovery of $\mathrm{CD} 4^{+} \mathrm{T}$ cells correlated with the number of naive phenotype CD4+ $\mathrm{T}$ cells found (Figure 7B) and with the frequency of TRECs in peripheral $\mathrm{CD}^{+} \mathrm{T}$ cells (Figure $7 \mathrm{C}$ ). Finally, the total $\mathrm{CD}^{+} \mathrm{T}$ cell number (at 2 years) correlated with thymic enlargement (maximal at 1 year) (Figure 7D). Thus, a thymic increase in size and cellularity was predictive of total $\mathrm{CD} 4^{+} \mathrm{T}$ cell levels after 2 years, consistent with the idea of a central role for thymic reconstruction in long-term recovery.
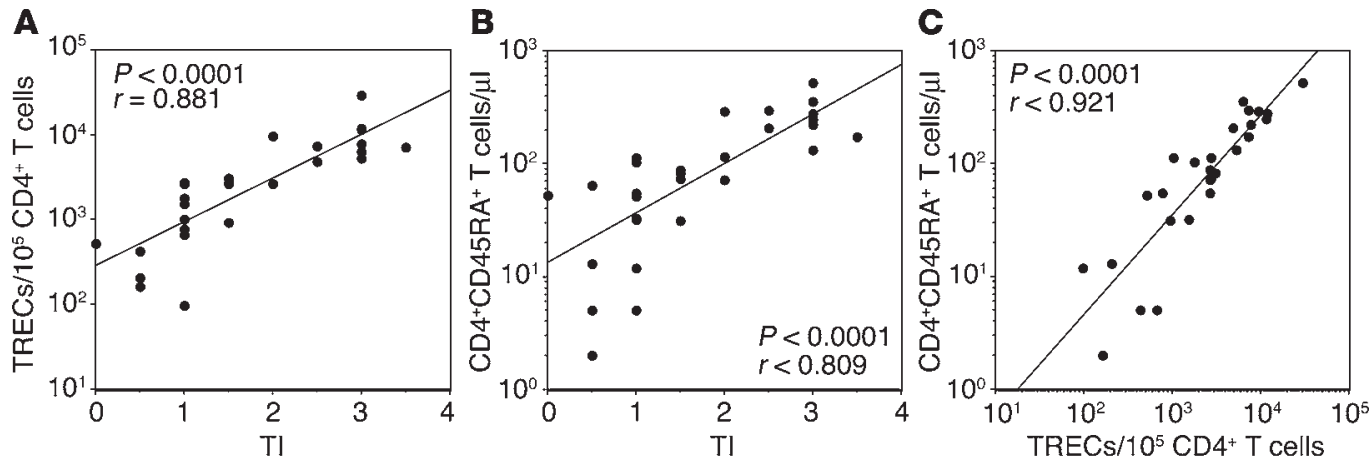

Figure 5

Correlated recovery of thymic size, TREC-bearing and naive CD4+ T cells. (A) Spearman nonparametric correlation between the highest TI attained within the first 2 years and the number of TRECs per $10^{5} \mathrm{CD} 4^{+} \mathrm{T}$ cells at 2 years. (B) Spearman nonparametric correlation between the highest $\mathrm{Tl}$ attained within the first 2 years and the number of naive (CD45RA $\left.{ }^{+} \mathrm{CD} 62 \mathrm{~L}^{+}\right) \mathrm{CD}^{+} \mathrm{T}$ cells per $\mu \mathrm{l}$ at 2 years. (C) Spearman nonparametric correlation between the frequency of TREC per $10^{5} \mathrm{CD} 4^{+} \mathrm{T}$ cells and the number of $\mathrm{CD} 45 \mathrm{RA}+\mathrm{CD} 62 \mathrm{~L}^{+} \mathrm{CD} 4^{+} \mathrm{T}$ cells per microliter of peripheral blood. 
CD45RA $^{+}$
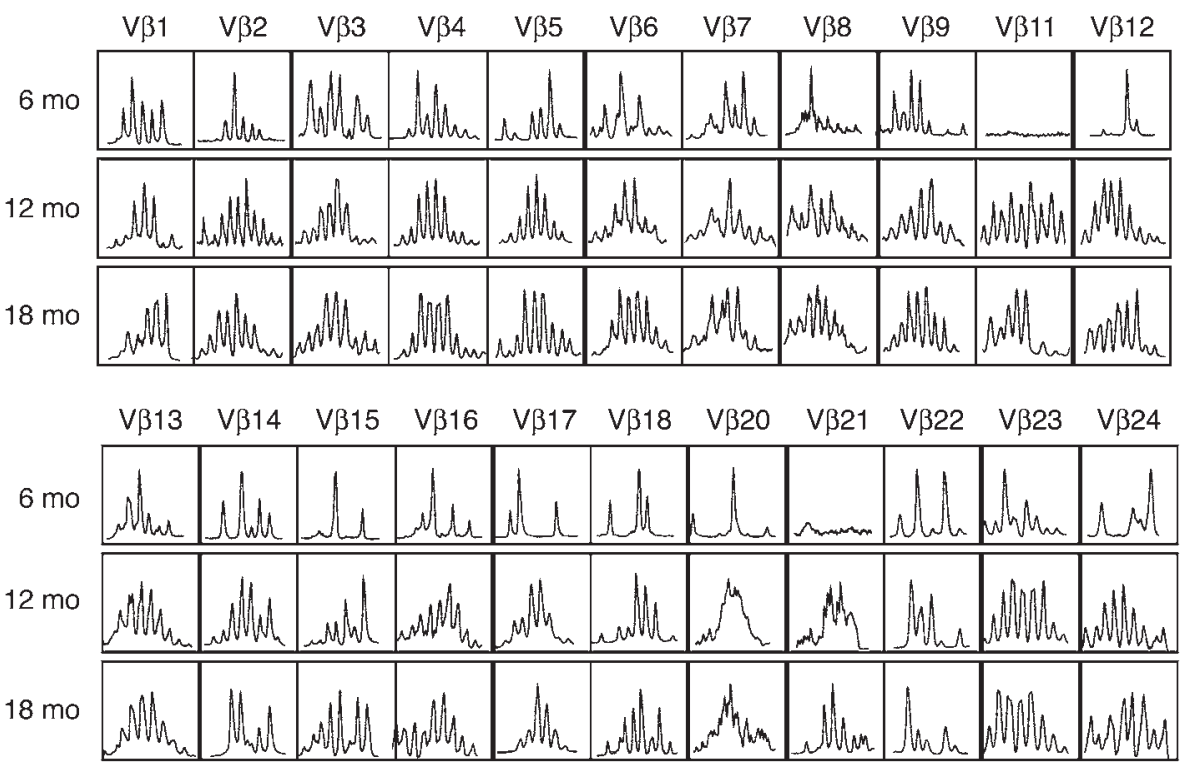

\section{Figure 6}

Naive $\mathrm{CD}^{+} \mathrm{T}$ cell repertoire diversity in an individual recovering more than $50 \%$ naive cells. At 6 months, 12 months, and 18 months, spectratypes were assessed by RT-PCR and CDR3 cDNA fragment length analysis for $23 \mathrm{~V} \beta$ families from 100,000 sorted CD45RA + CD4 + T cells. Although significantly oligoclonal at 6 months after APBSCT, within the first year after APBSCT, naive CD4+ $T$ cells recovered polyclonal spectratypes in most $\mathrm{V} \beta$ families.
In 17 patients monitored for 45-60 months after transplant, the total $\mathrm{CD}^{+} \mathrm{T}$ cell numbers continued to correlate strongly with naive $\mathrm{CD} 45 \mathrm{RA}^{+} \mathrm{CD} 62 \mathrm{~L}^{+} \mathrm{CD}^{+} \mathrm{T}$ cell number (Figure 7E). Seven patients with thymic insufficiency (a median of 60 naive CD4 cells) had fewer than 400 total CD4 ${ }^{+} \mathrm{T}$ cells (range, 195-376); 10 patients with strong thymopoietic renewal had more than 600 total CD4 ${ }^{+}$ cells (range, 618-952) with a median of 260 naive $\mathrm{CD}^{+}$cells.

Recovery of $\mathrm{CD}^{+} \mathrm{T}$ cell repertoire and functional memory balance. Return of $\mathrm{CD}^{+} \mathrm{T}$ cell populations to normal involves not only increases in naive cell numbers but also alterations in the memory $\mathrm{CD}^{+}$population. The memory CD4 populations are composed mainly of central memory (CM) cells (CD45RA-CD62 $\mathrm{L}^{+}$) and effector memory (EM) cells (CD45RA-CD62 $\left.\mathrm{L}^{-}\right)$; in the resting state the number of CM cells is greater than the number of EM cells in the peripheral blood (40). After undergoing several cycles of inductive therapy and the transplant conditioning regimen, the $\mathrm{CD}^{+} \mathrm{T}$ cells present express high levels of activation markers (HLA-DR and CD25; data not shown). Because of the loss of CD62L upon $\mathrm{T}$ cell activation, the population of CD45RA-CD62 $\mathrm{L}^{-} \mathrm{CD} 4^{+} \mathrm{T}$ cells that we measured early after transplant is a combination of resting EM and activated $\mathrm{CD}^{+} \mathrm{T}$ cells. These CD62 $\mathrm{L}^{-}$cells predominate, resulting in an inversion of the normal EM/CM ratio. To track changes in memory populations, we calculated the EM/CM ratio. This number becomes greater than 1 at the time of transplant and increases further during the early weeks of peripheral expansion. The highest EM/CM ratios among CD4 cells in the early after transplant period were found in individuals who had a parallel expansion of $\mathrm{CD}^{+} \mathrm{EM}$ (CD45RA $\left.{ }^{-} \mathrm{CD}^{2} 7^{-} \mathrm{CD} 28^{-}\right)$and EM RA (CD45RA $\left.{ }^{+} \mathrm{CD} 27^{-} \mathrm{CD} 28^{-}\right)$ $\mathrm{T}$ cell populations (40), possibly in response to latent viruses (data not shown). The early rapid decline reflected the loss of activated populations, in that levels of HLA-DR expression declined as well. There was also a gradual decline in the $\mathrm{EM} / \mathrm{CM}$ ratio that continued over the first 2 years (Figure $8 \mathrm{~A}$ ). We tested the role of renewed thymopoiesis in this return to a normal EM/CM ratio. In those individuals with a robust recovery of thymopoiesis, the EM/CM ratio returned to a low value more rapidly (Figure $8 \mathrm{~A})$. After 2 years, the EM/CM ratio was correlated with the frequency of TREC-bearing cells in the total CD4 population (Figure $8 \mathrm{~B}$ ). Thus, the recovery of naive cells, which were subsequently activated and added to the resting CM and EM pool, restores the EM/CM ratio. The CM CD62 $\mathrm{L}^{+} \mathrm{CD} 45 \mathrm{RA}^{+}$ CD 4 cells have been proposed to act as the stem cells of the CD4 memory population, with the capacity to rapidly interact with antigen on dendritic cells in the lymph nodes, to proliferate and to differentiate into effector $\mathrm{CD} 4$ cells that can migrate into the tissues (40). Our manuscript is the first to our knowledge to demonstrate a thymopoiesis-dependent resolution of the deficit in this population after transplant.

To further test the thymic contribution to functional memory cells, we separately assessed the TCR V $\beta$ repertoire diversity in the naive $\mathrm{CD}_{45 \mathrm{RA}^{+}}$and the memory $\mathrm{CD} 45 \mathrm{RA}^{-}$subpopulations of $\mathrm{CD}^{+} \mathrm{T}$ cells in sorted 100,000 -cell samples from 14 patients after 2 years ( 5 patients in their 30s, 4 in their 40 s, and 5 over 50 years of age). Whereas the CD45RA ${ }^{+}$repertoire would directly reflect thymopoiesis, the CD45RA- memory repertoire would depend upon the cumulative activation and conversion of competent naive cells into memory populations after therapy, as well as the gain and loss of activated oligoclonally expanded cell populations. In all patients, $\mathrm{CD} 45 \mathrm{RA}^{+}$repertoires had recovered significant diversity, with multiple peaks in most $V \beta$ families (Figures 6 and 9A), consistent with universal recovery of detectable levels of sjTREC and phenotypically naive cells. In some patients, however, the diversity of the CD45RA- population remained limited even after 2 years (Figure 9A). We quantified the repertoire diversity in the memory CD4 (CD45RA-) population at 2 years after transplant by counting the $V \beta$ families having at least 5 peaks on a spectratype derived from 100,000 sorted CD45RA- CD4 cells. Appropriate CDR3 peaks had to be spaced by multiples of $3 \mathrm{bp}$, have an amplitude of at least 3 times background, and have a peak height at least one-fifth that of the largest peak in the spectratype. After sorting for CD45RAcells for this analysis, the repertoire diversity in naive cells did not contribute to the diversity scores. Nevertheless, the number of diverse $V \beta$ families correlated strongly with the levels of naive 


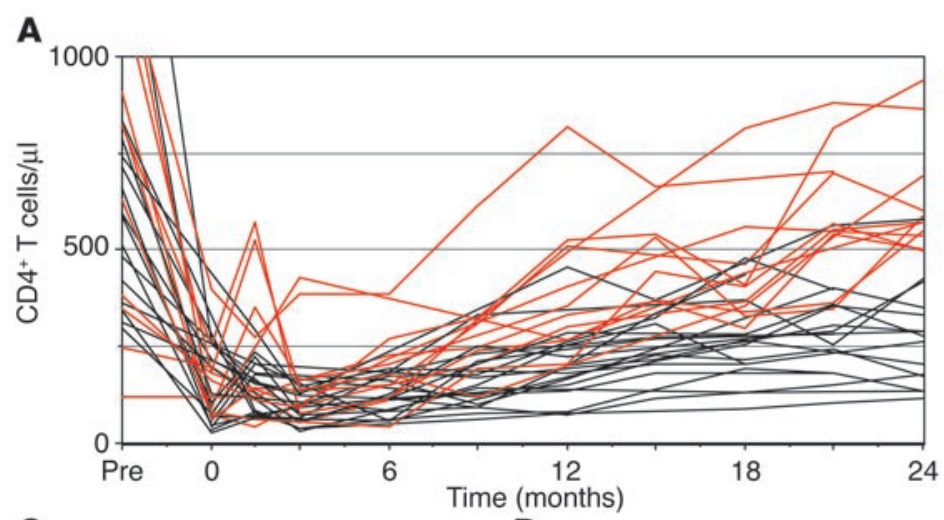

B

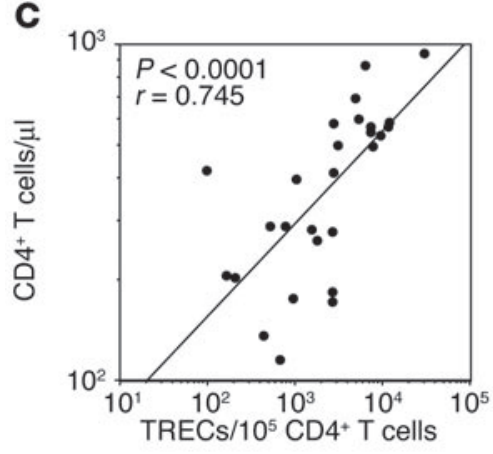

D

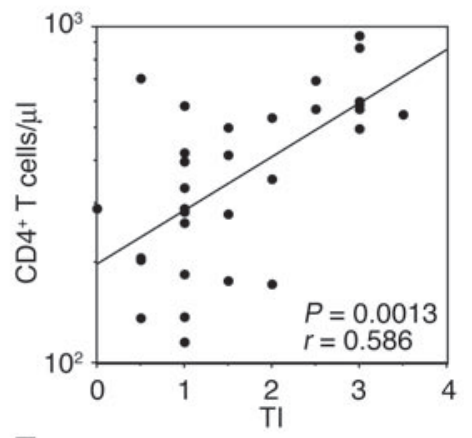

$\mathbf{E}$
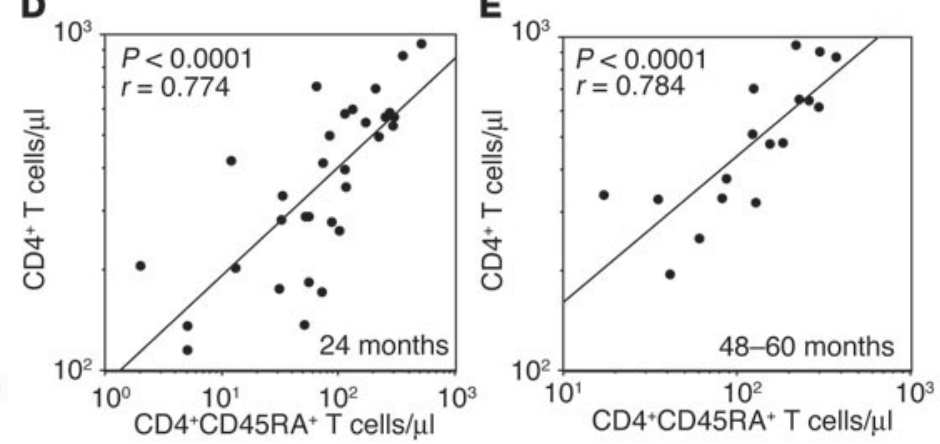

Figure 7

Correlation of quantitative recovery of total $C D 4^{+} T$ cell numbers with renewed thymopoiesis. (A) Individual time courses of CD4+ $T$ cell loss and recovery with APBSCT. Red lines indicate patients who attained frequencies of 3,000 TRECs or more per $10^{5} \mathrm{CD}^{+}$cells at 2 years. These same individuals tended to have the highest total CD4 recovery. PRE TRT, pretreatment. (B-D) Spearman nonparametric correlations demonstrate that long-term recovery of total CD4 number is predicted by maximum $\mathrm{TI}(\mathrm{B})$, typically achieved at 1 year, and is correlated with the frequency of TREC-bearing CD4 cells in the peripheral blood (C) and with the number of naive phenotype cells at 2 years (D). (E) Spearman nonparametric correlation demonstrates that even after 4-5 years, the recovery of robust thymopoiesis is the main determinant of total CD4+ T cell number.

$\mathrm{CD}^{+} \mathrm{T}$ cells, that is, with RTEs and with thymic size (Figure 9, $\mathrm{B}$ and $\mathrm{C})$. Hence, recovery of TCR repertoire diversity among memory $\mathrm{CD}^{+} \mathrm{T}$ cells is a consequence of increased thymic activity. Finally, in parallel with our observations on naive cell generation, we found that recovery of repertoire diversity in memory populations was inversely proportional with age (Figure 9D).

\section{Discussion}

The present study has addressed both the renewal of thymopoiesis after autologous transplant in middle-aged adults and the consequences of this renewal for peripheral CD4 populations. We have demonstrated that the capacity to renew thymopoiesis is strongly age dependent, even in a population limited to those over 30 years of age. We have reported a timeline of serial changes in the radiodense profile of the thymus in one third of the patients and have proposed that these reflect structural changes consistent with renewed thymopoiesis, as evidenced by the correlated recovery of sjTRECs, naive phenotype $\mathrm{CD} 4^{+} \mathrm{T}$ cells, and TCR V $\beta$ repertoire recovery in the peripheral blood. Furthermore, we have demonstrated that reactivated thymic function contributes decisively to the long-term recovery of total $\mathrm{CD}^{+} \mathrm{T}$ cell numbers. Successful recovery both of a normal EM/CM ratio and also of memory cells expressing a diverse TCR repertoire is directly dependent on renewed thymopoiesis.

The use of thymic CT imaging was first validated in pediatric patients in whom the recovery of naive cells in the peripheral blood correlated with thymic size in the first 6 months after chemo- therapy (25). In HIV patients, adult thymic imaging studies have correlated larger thymic profiles with higher TREC frequency and greater numbers of naive and total $\mathrm{CD} 4^{+} \mathrm{T}$ cells, particularly after HAART (27-29). The most informative studies of HIV-altered thymopoiesis, however, have monitored patients longitudinally, rather than merely examining a cross-section of patients. In serial studies of HIV-positive patients on HAART, those with larger increases in thymic volume have shown larger increases in CD4 numbers over the course of the therapy $(41,42)$. In contrast, serial studies of patients receiving IL-2 therapy that have shown no overall increase in thymic size have confirmed a role for IL-2 therapy in peripheral expansion but not thymopoiesis (43). Thus, there is now a consistent body of longitudinal studies linking long-term shifts in thymic volume over time in adults with effective thymopoiesis.

In the absence of thymic biopsy, it cannot be confirmed that the development of an enlarged radiodense thymic profile after transplant represents an expansion of thymic cortex and medullary tissue, reversing the encroachment of adipose and connective tissue that occupies most of the adult thymus. Nonetheless, 3 points are worth noting. First, the serial analysis of thymic profiles demonstrated a pattern of consistent increases in size and radiodensity with durations lasting from months to years. Second, the maximum thymic size attained correlated with the levels of naive and TREC-bearing CD4 ${ }^{+} \mathrm{T}$ cells and with the recovery of a broad TCR repertoire, consistent with renewed thymopoiesis. Finally, 10 of the 12 patients with notable TI changes attained a significantly larger, 

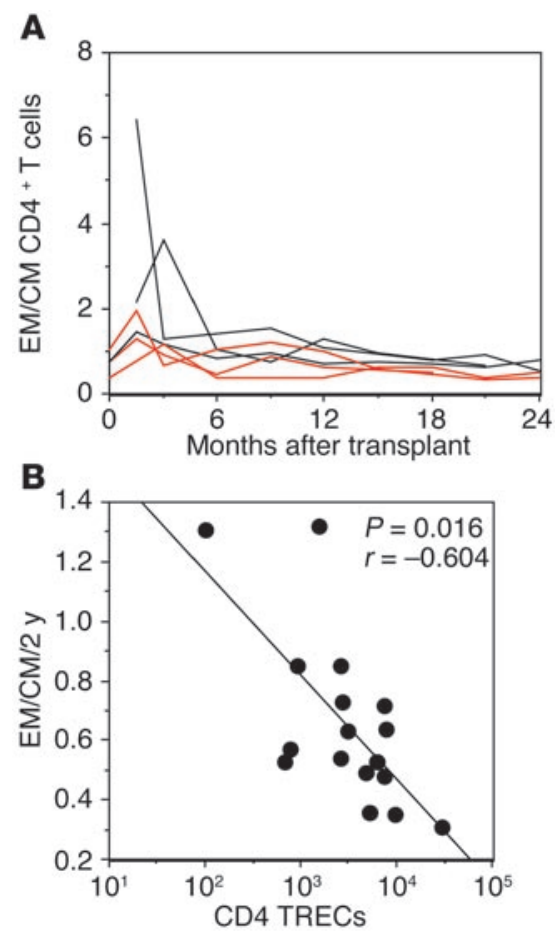

more densely cellular profile than was present pretreatment, and peripheral blood CD4 TREC frequencies were on average 1.8 times the pretreatment frequencies (data not shown). These suggest that the generation of new $\mathrm{T}$ cells after transplant involved structural thymic change, not merely cumulative production through the limited cortical-medullary tissue of the pretreatment thymus.

The thymus undergoes progressive structural changes with age $(5,44)$. Perivascular space expands and thymic medulary and cortical tissue are reduced to small islands surrounded by adipose and fibrous tissue (5). The levels of thymopoiesis gradually diminish (1) and the numbers of naive $\mathrm{T}$ cells and the repertoire diversity in the periphery decline (4). Multiple factors may contribute to thymic involution. First, aging reduces the frequency of prethymic $T$ cell progenitors within the hematopoietic stem cells $(45,46)$. Umbilical cord stem cells result in higher TREC frequencies than does bone marrow, even in young adult recipients (38). Second, aging may result in extrathymic changes that limit thymopoiesis. Growth hormone (GH) and IGF-1 decline with age; as concentrations decrease systemically, the stromal cells in the thymus may convert to adipose cells (47). While GH and IGF reduce thymocyte apoptosis and increase thymic epithelial cytokine production, gonadal steroids after puberty have the opposite effect. The decrease in the former may contribute to the increase in adipose tissue in the thymus; the increase in the latter, to the reduction in cortical thymocytes. Finally, the thymic microenvironment changes. Expression of critical epithelial genes such as those encoding keratin-8, Foxn1, and in murine systems, IL-7, decline and intrathymic production of cytokines such as LIF, OSM, and IL-6 may increase $(6,48,49)$. These factors are not mutually exclusive but instead may all contribute to thymic involution with age.

What then could contribute to the re-establishment of thymopoiesis after transplant? One factor is homeostatic cytokines. Circulating IL-7 levels increase during cytoreductive therapies, when consumption by lymphocytes falls $(50,51)$. These elevated

\section{Figure 8}

Effect of naive $\mathrm{CD} 4^{+} \mathrm{T}$ cells' recovery on EM/CM ratio. (A) Time course of shifts in the $\mathrm{EM} / \mathrm{CM} \mathrm{CD} 4{ }^{+} \mathrm{T}$ cell ratio in 6 representative patients. Red lines indicate patients who had a strong recovery of thymopoiesis (TRECs $/ 10^{5} \mathrm{CD}^{+} \mathrm{T}$ cells at least 3,000 at 2 years). (B) Spearman nonparametric correlation demonstrates that long-term recovery of the ratio of EM to $\mathrm{CM} \mathrm{CD4}{ }^{+} \mathrm{T}$ cells correlates with the frequency of TRECbearing cells in the CD4 population.

levels support expansion of residual $\mathrm{T}$ cell populations and stabilize these cells against apoptosis $(52,53)$. Elevated IL-7 may not enhance the rate of thymopoiesis in intact young mice (53) but may support thymopoiesis in cytoreduced irradiated or aged mice (54-56). A second factor is "space." Thymic double-negative progenitors $\left(\mathrm{CD}^{-}{ }^{-} \mathrm{CD} 8^{-}\right)$compete for limited numbers of stromal sites (57). Cytoreductive regimens might open "space" for early thymic progenitor (ETP) commitment and engraftment in the thymus. The final factor may hinge on the interaction between epithelial stroma and $\mathrm{T}$ cell precursors in thymic organogenesis. Maturation of stromal precursors into cortical and medullary stroma is dependent upon interactions with thymocytes (58-60). The slow increase in thymic size and radiodense cellularity that we observed in adults may correspond to a rebuilding of the thymus by interacting ETP and stroma. The age dependence of the renewal of thymopoiesis may reflect the limits of this regenerative capacity.

The renewal of thymic function after $\mathrm{T}$ cell depletion had broad consequences on the restoration of homeostatic balance in memory as well as naive $T$ cell pools. First, we have demonstrated that regardless of any early peripheral expansions of residual $\mathrm{CD}^{+} \mathrm{T}$ cell populations, the long-term recovery of quantitatively normal levels of $\mathrm{CD}^{+} \mathrm{T}$ cells is strongly based upon renewed thymopoiesis. Individuals with evidence of renewed thymopoiesis were capable of quantitatively restoring normal levels of CD4 cells; those lacking effective thymopoiesis remained deficient in CD4 populations for as long as 5 years after transplant. Second, renewed thymopoiesis can restore the proportions of memory subpopulations, which are altered by cytoreduction and inflammation during transplant. Although this study could not distinguish between activated and EM $\mathrm{CD}^{+}$populations in the early period after transplant, the long-term recovery of the ratio of resting $\mathrm{EM}$ to $\mathrm{CM} \mathrm{CD}^{+}$cells was enhanced by renewal of thymopoiesis. This effect on memory populations is consistent with an ongoing process of utilization of cells from the naive pool, which then restores resting CM pools. Expanding the naive pool would therefore contribute to balancing memory populations. The same relationship underlies the dependence upon thymopoiesis of the recovery of TCR V $\beta$ repertoire diversity in the memory CD4 population. Studies of TCR repertoire diversity among total $\mathrm{CD}^{+}$or $\mathrm{CD}^{+} \mathrm{T}$ cells reflect mainly the frequency of naive cells within the analyzed population. By separately assessing repertoire in the memory CD 4 cells, our study demonstrated that the recovery of a diverse TCR repertoire in the memory population was dependent upon renewed thymopoiesis. Just as with restoring the homeostatic balance of EM/CM ratios, the recovery of TCR repertoire diversity in memory cells requires the presence of a high frequency of functionally competent naive cells as a source.

Certainly, the capacity for renewed thymopoiesis is not entirely lost with aging or cytoreductive therapy. Even those patients with the poorest total CD4 recovery demonstrated modest increases in the frequency of naive phenotype $\mathrm{CD}^{+} \mathrm{T}$ cells, measurable levels 
A

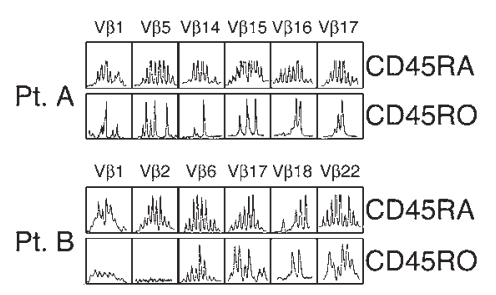

B

C
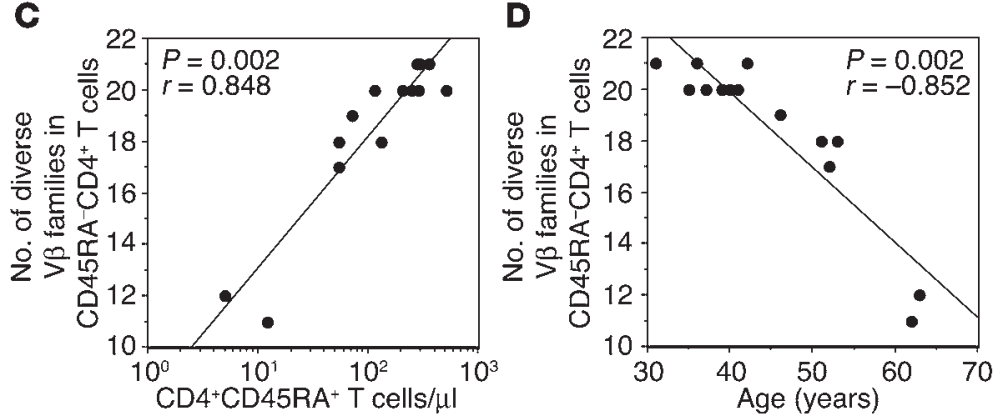

Figure 9

Effect of renewed thymopoiesis and age on TCR repertoire diversity. (A) Repertoire diversity in naive versus memory CD4 ${ }^{+} \mathrm{T}$ cells in 2 individuals, patient $\mathrm{A}$ (Pt. A) and $\mathrm{Pt}$. B, with less than $15 \%$ naive CD4+ T cells after $2-4$ years. Representative spectratypes of several $\mathrm{V} \beta$ families demonstrate that naive $\mathrm{CD} 4^{+}$populations have polyclonal spectratypes, whereas memory/activated CD45RA- CD4 ${ }^{+} \mathrm{T}$ cells have more limited diversity. (B-D) Spearman correlation demonstrates that recovery of diverse CDR3 repertoire in memory/activated (CD45RA $\left.{ }^{-}\right) \mathrm{CD}^{+} \mathrm{T}$ cells is correlated with recovery of thymopoiesis, as assessed by $\mathrm{TI}(\mathrm{B})$ and number of naive CD45RA + CD4+ $T$ cells (C). (D) Spearman correlation demonstrates that the capacity to recover a broad TCR repertoire after transplant is dependent upon patient age.

of TRECs, and diverse TCR repertoires in their CD45RA ${ }^{+} \mathrm{CD} 4^{+}$ subpopulations. Yet an individual's age was the key determinant of both the likelihood and the time required to quantitatively restore peripheral $\mathrm{CD} 4^{+} \mathrm{T}$ cell populations and to re-establish normal repertoire diversity in memory populations as well (Figure 9D). These consequences are particularly relevant when autologous transplant is considered as therapy for nonmalignant disorders, such as autoimmune diseases. In cases of autoimmune disease, therapies depleting lymphoid populations can provide a prolonged remission by depletion of self-reactive cells. Autologous transplant has been explored in recent years as a therapy that could lead to a more extensive lymphodepletion and could potentially result in a longer remission. This has to be balanced against the toxicity and potential risk of prolonged immune deficits due to failure to reconstitute adequate $\mathrm{T}$ cell populations. The information provided by our study provides a better estimate of the risks for such failure and age-based criteria to appropriately select patients. The data presented here demonstrate that patients between 30 and 40 years of age have a high probability of renewed thymopoiesis and recovery of $\mathrm{CD}^{+} \mathrm{T}$ cell populations. The frequency of effective renewal of thymopoiesis declines significantly in patients over 40 and is less than $10 \%$ for those over 50 years of age.

Our work suggests that the quantitative capacity for new $\mathrm{T}$ cell maturation is dependent upon a re-establishment of thymic structure. This process clearly requires prolonged time to take effect, an observation with implications for clinical studies seek- ing to enhance thymic function. Moreover, a deeper understanding of the mechanisms of thymic regulation is critical for the development of new strategies to enhance immune reconstitution.

\section{Methods}

Patients. Patients with stage III and IV breast cancer (median age, 45; range, 31-64) treated with at least 3 cycles of paclitaxel (continuous i.v. infusion of $160 \mathrm{mg} / \mathrm{m}^{2}$ over 72 hours) and cyclophosphamide $\left(900 \mathrm{mg} / \mathrm{m}^{2} /\right.$ day i.v., given over 1 hour on days 1, 2, and 3], with G-CSF at a dose of $5 \mu \mathrm{g} / \mathrm{kg} /$ day administered s.c. from day 5 until the absolute neutrophil count (ANC) returned to a level of more than 1,000 cells $/ \mathrm{mm}^{3}$. Peripheral blood stem cells (PBSCs) were collected after cycle 2, when the $\mathrm{CD} 34^{+}$count was more than 20 cells/ $\mu$ l, by apheresis. Patients who had not received an anthracycline before entry to the study received 4 cycles of doxorubicin $\left(60 \mathrm{mg} / \mathrm{m}^{2}\right)$ and cyclophosphamide $\left(600 \mathrm{mg} / \mathrm{m}^{2}\right)$ given i.v. every 3 weeks. The conditioning regimen consisted of i.v. infusion on days $-6,-5$, and -4 of melphalan (total dose, $160 \mathrm{mg} / \mathrm{m}^{2}$ ) and then etoposide (total dose, $1,800 \mathrm{mg} / \mathrm{m}^{2}$ ). PBSCs were reinfused at day 0 . G-CSF at a dose of $5 \mu \mathrm{g} / \mathrm{kg} /$ day was started on day 0 and was continued until the ANC was 10,000 or more cells $/ \mathrm{mm}^{3}$. Of the patients entering the protocol, 33 have been monitored for 21-60 months after transplant by serial thoracic CT scans and flow cytometry; 26 of these have been tested at 1 or more time points for TREC frequency and 14 have been examined for $V \beta$ spectratype in naive and memory CD4 cells. This study (96C-0104) was approved by the National Cancer Institute Institutional Review Board (Bethesda, Maryland, USA). Informed written consent was obtained from each patient.

Flow cytometric analyses. Flow cytometry was performed in a Clinical Laboratory Improvement Amendment-certified laboratory (Science Applications International Corp.). The absolute numbers of $\mathrm{CD}^{+} \mathrm{CD}^{+}$cells per microliter of blood were calculated based upon the percentages of these cells in the lymphocyte gate, the percentage of lymphocytes (defined as CD45 $5^{\text {bright }}$, low side scatter), and complete blood counts performed in the NIH Clinical Center Laboratory. Naive (CD45RA $\left.{ }^{+} \mathrm{CD} 62 \mathrm{~L}^{+}\right)$, EM (CD45RA-CD62L-), and CM (CD45RA-CD62 $\left.\mathrm{L}^{+}\right)$ $\mathrm{CD}^{+} \mathrm{T}$ cells were assessed pretreatment, at transplant, at 1.5 months after transplant, and at 3-month intervals for the first 2 years and annually for the next 3 years after transplant. Cells were sorted from cryopreserved samples for repertoire or TREC analysis using a FACSVantage (BD Biosciences - Immunocytometry Systems). All reagents were obtained from BD Biosciences - Pharmingen.

Thymic size grading. CT scans of the chest were performed for staging or follow-up at sites of disease using either a GE 9800 or a GE Hi-Speed Advantage system (General Electric Co.), using 10-mm increments in scan reconstruction thickness and using i.v. contrast enhancement unless contraindicated. Chest CT scans of the patients were reviewed by 2 diagnostic radiologists blinded to the CD 4 counts of the patients, and were compared with patient examples of the standard thymic grades, based on an ordinal grading system (Figure 1) (28). Patients were assessed at pretreatment, at the end of adjuvant chemotherapy, at 6 weeks after transplant, at 3- to 6-month intervals after transplant for the first 24 months, and annually thereafter.

$V \beta T C R$ spectratyping. Variation in the lengths of the $V \beta C D R 3$ regions was assessed in naive $\left(\mathrm{CD}^{+} \mathrm{CD} 45 \mathrm{RA}^{+}\right)$and memory $\left(\mathrm{CD} 4^{+} \mathrm{CD} 45 \mathrm{RA}{ }^{-}\right) \mathrm{CD}^{+} \mathrm{T}$ cells, sorted by the FACSVantage SE into 100,000 cell aliquots, at greater than 99\% purity. RNA isolated using Trizol (Gibco Life Sciences) in the presence 
of carrier tRNA and glycogen was converted to cDNA using oligo(dT) as a primer for reverse transcription (First Strand cDNA kit; Roche Diagnostics Corp.). The cDNA was amplified first in 23 separate PCRs, each containing 1 specific human $V \beta$ subfamily primer coupled with a consensus $\beta$-constant region (BC) primer, followed by a 10-cycle run-off nested PCR reaction (4) utilizing a Cy5-labeled internal BC primer (Integrated DNA Technology). Reaction products were mixed with formamide dye-loading buffer with the addition of Cy5.5-labeled 100-, 150-, and 200-bp size markers (Visible Genetics), were heated at $80^{\circ} \mathrm{C}$ for 2 minutes, and were applied to a prerun $6 \%$ acrylamide-urea sequencing gel cassette (Visible Genetics). Gels were run on the Gene Blaster automated sequencer (Visible Genetics) for analysis of fragment length, and data were analyzed using GeneObjects software (Visible Genetics). Spectratype peaks were counted if they occurred with a separation of $3 \mathrm{bp}$, had a peak height at least 3 times background and at least one-fifth that of the largest peak for that CDR3 spectratype.

TREC analysis. The sjTRECs were assessed in sorted 100,000-cell aliquots of $\mathrm{CD}^{+}{ }^{+} \mathrm{CD} 4{ }^{+}$cells by real-time quantitative PCR on an ABI 7700 system (Applied Biosystems) as described previously (22). Briefly, cells were lysed in $100 \mu \mathrm{g} / \mathrm{ml}$ proteinase $\mathrm{K}$ (Boehringer) for 1 hour at $56^{\circ} \mathrm{C}$ and then for 10 minutes at $95^{\circ} \mathrm{C}$ at a concentration of $10^{7} \mathrm{cells} / \mathrm{ml}$. Real-time quantitative PCR was performed on $5 \mu \mathrm{l}$ of cell lysates (equivalent to 50,000 cells) with the primers 5'-CACATCCCTTTCAACCATGCT-3' and 5'-GCCAGCTGCAGGGTTTAGG-3' and probe FAM-5'-ACACCTCTGGTTTTTGTAAAGGTGCCCACT-TAMRA (Biosource International). PCRs contained 0.5 U Platinum Taq polymerase (Invitrogen Corp.) and $3.5 \mathrm{mM} \mathrm{MgCl}_{2}, 9.2 \mathrm{mM}$ dNTPs, $500 \mathrm{nM}$ of each primer, $150 \mathrm{nM}$ probe, and Blue- 636 reference dye (MegaBases). Conditions were $95^{\circ} \mathrm{C}$ for 5 minutes, $95^{\circ} \mathrm{C}$ for 30 seconds, and $60^{\circ} \mathrm{C}$ for 1 minute for 40 cycles. A standard curve was created by cloning of the signal-joint fragment and a standard curve was plotted $\left(10^{7}-10^{2}\right.$ TREC copies/well), and TREC values for samples were calculated using Sequence
Detection Systems software version 1.9.1 (Applied Biosystems). Samples were analyzed in duplicate and the results were averaged.

Statistical analysis. Correlations were tested with the nonparametric Spearman correlation test. TI data were compared over 3 age groups using nonparametric Kaplan-Meier survival analysis, with time to recovery of normal thymic size (a TI of 2) considered the time to endpoint and data from patients not recovering to that size within 24 months being censored. Differences between the age groups were tested by the Mantel-Cox log-rank test. All statistical analyses were performed using the program Statview 5.0 (Abacus Concepts Inc.) for Macintosh computers.

\section{Acknowledgments}

We appreciate the contributions of the clinical staff of the Experimental Transplantation and Immunology Branch in providing patient materials; Daniel Douek of the National Institute of Allergy and Infectious Diseases Vaccine Research Center for establishing the TREC assay; William Kopp and Louise Finch of the Section for Allergic and Immunologic Disease for performing clinical flow cytometry; and William Telford and Veena Kapoor of the Experimental Transplantation and Immunology Branch Flow Cytometry Core for CD4 subset sorting.

Received for publication July 21, 2004, and accepted in revised form January 25, 2005.

Address correspondence to: Frances T. Hakim, Building 10, Room 12N226, Experimental Transplantation and Immunology Branch, National Cancer Institute, National Institutes of Health, 10 Center Drive, Bethesda, Maryland 20892, USA. Phone: (301) 402-3627; Fax: (301) 402-8690; E-mail: fhakim@helix.nih.gov.
1. Douek, D.C., and Koup, R.A. 2000. Evidence for thymic function in the elderly. Vaccine. 18:1638-1641.

2. Jamieson, B.D., et al. 1999. Generation of functional thymocytes in the human adult. Immunity. 10:569-575.

3. Douek, D.C., et al. 1998. Changes in thymic function with age and during the treatment of HIV infection. Nature. 396:690-695.

4. Schwab, R., et al. 1997. Expanded CD4+ and CD8+ $\mathrm{T}$ cell clones in elderly humans. J. Immunol. 158:4493-4499.

5. Haynes, B.F., Markert, M.L., Sempowski, G.D., Patel, D.D., and Hale, L.P. 2000. The role of the thymus in immune reconstitution in aging, bone marrow transplantation, and HIV-1 infection. Annu. Rev. Immunol. 18:529-560.

6. Sempowski, G.D., et al. 2000. Leukemia inhibitory factor, oncostatin M, IL-6, and stem cell factor mRNA expression in human thymus increases with age and is associated with thymic atrophy. J. Immunol. 164:2180-2187.

7. Haynes, B.F., Sempowski, G.D., Wells, A.F., and Hale, L.P. 2000. The human thymus during aging. Immunol. Res. 22:253-261.

8. Fry, T.J., and Mackall, C.L. 2002. Current concepts of thymic aging. Springer Semin. Immunopathol. 24:7-22.

9. Goldrath, A.W., Bogatzki, L.Y., and Bevan, M.J. 2000. Naive T cells transiently acquire a memorylike phenotype during homeostasis-driven proliferation. J. Exp. Med. 192:557-564.

10. Tough, D.F., and Sprent, J. 1994. Turnover of naive- and memory-phenotype T cells. J. Exp. Med. 179:1127-1135.

11. Geginat, J., Lanzavecchia, A., and Sallusto, F. 2003. Proliferation and differentiation potential of human CD8+ memory T-cell subsets in response to antigen or homeostatic cytokines. Blood. 101:4260-4266.
12. Geginat, J., Sallusto, F., and Lanzavecchia, A. 2001. Cytokine-driven proliferation and differentiation of human naive, central memory, and effector memory CD4(+) T cells. J. Exp. Med. 194:1711-1719.

13. Mackall, C.L., et al. 1996. Thymic-independent T cell regeneration occurs via antigen-driven expansion of peripheral $\mathrm{T}$ cells resulting in a repertoire that is limited in diversity and prone to skewing. J. Immunol. 156:4609-4616.

14. Bahceci, E., et al. 2003. Early reconstitution of the T-cell repertoire after non-myeloablative peripheral blood stem cell transplantation is from postthymic T-cell expansion and is unaffected by graftversus-host disease or mixed chimaerism. $B r . J$. Haematol. 122:934-943.

15. Fallen, P.R., et al. 2003. Factors affecting reconstitution of the T cell compartment in allogeneic haematopoietic cell transplant recipients. Bone Marrow Transplant. 32:1001-1014.

16. Hakim, F.T., et al. 1997. Constraints on CD4 recovery postchemotherapy in adults: thymic insufficiency and apoptotic decline of expanded peripheral CD4 cells. Blood. 90:3789-3798.

17. Mackall, C.L., Granger, L., Sheard, M.A., Cepeda, R., and Gress, R.E. 1993. T-cell regeneration after bone marrow transplantation: differential CD45 isoform expression on thymic-derived versus thymic-independent progeny. Blood. 82:2585-2594.

18. Brugnoni, D., et al. 1999. Immune reconstitution after bone marrow transplantation for combined immunodeficiencies: down-modulation of $\mathrm{Bcl}-2$ and high expression of CD95/Fas account for increased susceptibility to spontaneous and activation-induced lymphocyte cell death. Bone Marrow Transplant. 23:451-457.

19. Lin, M.T., et al. 2000. Increased apoptosis of peripheral blood $\mathrm{T}$ cells following allogeneic hematopoi- etic cell transplantation. Blood. 95:3832-3839.

20. Poulin, J.F., et al. 2003. Evidence for adequate thymic function but impaired naive T-cell survival following allogeneic hematopoietic stem cell transplantation in the absence of chronic graft-versus-host disease. Blood. 102:4600-4607.

21. Lewin, S.R., et al. 2002. Direct evidence for new $\mathrm{T}$-cell generation by patients after either T-celldepleted or unmodified allogeneic hematopoietic stem cell transplantations. Blood. 100:2235-2242.

22. Douek, D.C., et al. 2000. Assessment of thymic output in adults after haematopoietic stem-cell transplantation and prediction of T-cell reconstitution. Lancet. 355:1875-1881.

23. Mackall, C.L., et al. 2000. Prolonged CD4 depletion after sequential autologous peripheral blood progenitor cell infusions in children and young adults. Blood. 96:754-762.

24. Nordoy, T., et al. 1999. Persistent changes in the immune system 4-10 years after ABMT. Bone Marrow Transplant. 24:873-878.

25. Mackall, C.L., et al. 1995. Age, thymopoiesis, and CD4+ T-lymphocyte regeneration after intensive chemotherapy. N. Engl.J. Med. 332:143-149.

26. Hara, M., McAdams, H.P., Vredenburgh, J.J., Herndon, J.E., and Patz, E.F., Jr. 1999. Thymic hyperplasia after high-dose chemotherapy and autologous stem cell transplantation: incidence and significance in patients with breast cancer. AJR Am.J. Roentgenol. 173:1341-1344.

27. Kolte, L., et al. 2002. Association between larger thymic size and higher thymic output in human immunodeficiency virus-infected patients receiving highly active antiretroviral therapy. J. Infect. Dis. 185:1578-1585.

28. McCune, J.M., et al. 1998. High prevalence of thymic tissue in adults with human immunodeficiency virus-1 infection. J. Clin. Invest. 101:2301-2308. 
29. Smith, K.Y., et al. 2000. Thymic size and lymphocyte restoration in patients with human immunodeficiency virus infection after 48 weeks of zidovudine, lamivudine, and ritonavir therapy. J. Infect. Dis. 181:141-147.

30. Klein, A.K., et al. 2001. T-cell recovery in adults and children following umbilical cord blood transplantation. Biol. Blood Marrow Transplant. 7:454-466.

31. Hazenberg, M.D., et al. 2002. T-cell receptor excision circle and T-cell dynamics after allogeneic stem cell transplantation are related to clinical events. Blood. 99:3449-3453.

32. Douek, D.C., et al. 2001. Evidence for increased T cell turnover and decreased thymic output in HIV infection. J. Immunol. 167:6663-6668.

33. Weinberg, K., et al. 2001. Factors affecting thymic function after allogeneic hematopoietic stem cell transplantation. Blood. 97:1458-1466.

34. Dumont-Girard, F., et al. 1998. Reconstitution of the T-cell compartment after bone marrow transplantation: restoration of the repertoire by thymic emigrants. Blood. 92:4464-4471.

35. Fallen, P.R., et al. 2003. Identification of non-naive CD4+CD45RA+ $T$ cell subsets in adult allogeneic haematopoietic cell transplant recipients. Bone Marrow Transplant. 32:609-616.

36. Gorski, J., et al. 1994. Circulating T cell repertoire complexity in normal individuals and bone marrow recipients analyzed by CDR3 size spectratyping. Correlation with immune status. J. Immunol. 152:5109-5119.

37. Orsini, E., et al. 2000. Changes in T cell receptor repertoire associated with graft-versus- tumor effect and graft-versus-host disease in patients with relapsed multiple myeloma after donor lymphocyte infusion. Bone Marrow Transplant. 25:623-632.

38. Talvensarri, K., et al. 2002. A broad T-cell repertoire diversity and an efficient thymic function indicate a favorable long-term immune reconstitution after cord blood stem cell transplantation. Blood. 99:1458-1464.

39. Verfuerth, S., et al. 2000. Longitudinal monitoring of immune reconstitution by CDR3 size spectratyping after T-cell-depleted allogeneic bone marrow transplant and the effect of donor lymphocyte infusions on T-cell repertoire. Blood. 95:3990-3995.

40. Sallusto, F., Geginat, J., and Lanzavecchia, A. 2004. Central memory and effector memory $\mathrm{T}$ cell subsets: function, generation, and maintenance. Annu. Rev. Immunol. 22:745-763.

41. Rubio, A., et al. 2002. Changes in thymus volume in adult HIV-infected patients under HAART: correlation with the T-cell repopulation. Clin. Exp. Immunol. 130:121-126.

42. Ruiz-Mateos, E., et al. 2003. Comparison of thymic function-related markers to predict early CD4 Tcell repopulation in adult HIV-infected patients on HAART. Antivir. Ther. 8:289-294.

43. Lu, A.C., et al. 2003. Increases in CD4+ T lymphocytes occur without increases in thymic size in HIVinfected subjects receiving interleukin-2 therapy. J. Acquir. Immune Defic. Syndr. 34:299-303.

44. Mackall, C.L., Punt, J.A., Morgan, P., Farr, A.G., and Gress, R.E. 1998. Thymic function in young/old chimeras: substantial thymic $\mathrm{T}$ cell regenerative capacity despite irreversible age-associated thymic involution. Eur. J. Immunol. 28:1886-1893.

45. Sharp, A., Kukulansky, T., and Globerson, A. 1990. In vitro analysis of age-related changes in the developmental potential of bone marrow thymocyte progenitors. Eur. J. Immunol. 20:2541-2546.

46. Hirokawa, K., Kubo, S., Utsuyama, M., Kurashima, C., and Sado, T. 1986. Age-related change in the potential of bone marrow cells to repopulate the thymus and splenic T cells in mice. Cell. Immunol. 100:443-451.

47. Linton, P.J., and Dorshkind, K. 2004. Age-related changes in lymphocyte development and function. Nat. Immunol. 5:133-139.

48. Ortman, C.L., Dittmar, K.A., Witte, P.L., and Le, P.T. 2002. Molecular characterization of the mouse involuted thymus: aberrations in expression of transcription regulators in thymocyte and epithelial compartments. Int. Immunol. 14:813-822.

49. Andrew, D., and Aspinall, R. 2002. Age-associated thymic atrophy is linked to a decline in IL-7 production. Exp. Gerontol. 37:455-463.
50. Bolotin, E., Annett, G., Parkman, R., and Weinberg, K. 1999. Serum levels of IL-7 in bone marrow transplant recipients: relationship to clinical characteristics and lymphocyte count. Bone Marrow Transplant. 23:783-788.

51. Fry, T.J., et al. 2001. A potential role for interleukin-7 in T-cell homeostasis. Blood. 97:2983-2990.

52. Fry, T.J., Christensen, B.L., Komschlies, K.L., Gress, R.E., and Mackall, C.L. 2001. Interleukin-7 restores immunity in athymic T-cell-depleted hosts. Blood. 97:1525-1533.

53. Chu, Y.W., et al. 2004. Exogenous IL-7 increases recent thymic emigrants in peripheral lymphoid tissue without enhanced thymic function. Blood. 104:1110-1119.

54. Andrew, D., and Aspinall, R. 2001. Il-7 and not stem cell factor reverses both the increase in apoptosis and the decline in thymopoiesis seen in aged mice. J. Immunol. 166:1524-1530.

55. Alpdogan, O., et al. 2001. Administration of interleukin-7 after allogeneic bone marrow transplantation improves immune reconstitution without aggravating graft-versus-host disease. Blood. 98:2256-2265.

56. Bolotin, E., Smogorzewska, M., Smith, S., Widmer, M., and Weinberg, K. 1996. Enhancement of thymopoiesis after bone marrow transplant by in vivo interleukin-7. Blood. 88:1887-1894.

57. Prockop, S.E., and Petrie, H.T. 2004. Regulation of thymus size by competition for stromal niches among early $\mathrm{T}$ cell progenitors. J. Immunol. 173:1604-1611.

58. van Ewijk, W., Hollander, G., Terhorst, C., and Wang, B. 2000. Stepwise development of thymic microenvironments in vivo is regulated by thymocyte subsets. Development. 127:1583-1591.

59. Naquet, P., Naspetti, M., and Boyd, R. 1999. Development, organization and function of the thymic medulla in normal, immunodeficient or autoimmune mice. Semin. Immunol. 11:47-55.

60. Klug, D.B., et al. 1998. Interdependence of cortical thymic epithelial cell differentiation and T-lineage commitment. Proc. Natl. Acad. Sci.U. S. A. 95:11822-11827. 